\title{
Surgical Treatment of Sporadic Pancreatic Neuroendocrine Tumors: A State of the Art Review
}

\author{
Sven-Petter Haugvik, ${ }^{1,2}$ Knut Jørgen Labori, ${ }^{1}$ Bjørn Edwin, ${ }^{1,2,3}$ Øystein Mathisen, ${ }^{1}$ \\ and Ivar Prydz Gladhaug 1,2 \\ ${ }^{1}$ Department of Hepato-Pancreato-Biliary Surgery, Rikshospitalet, Oslo University Hospital, Sognsvannsveien 20, 0372 Oslo, Norway \\ ${ }^{2}$ Institute of Clinical Medicine, University of Oslo, Kirkeveien 166, 0450 Oslo, Norway \\ ${ }^{3}$ Interventional Centre, Rikshospitalet, Oslo University Hospital, Sognsvannsveien 20, 0372 Oslo, Norway
}

Correspondence should be addressed to Sven-Petter Haugvik, svhaug@ous-hf.no

Received 12 October 2012; Accepted 25 November 2012

Academic Editors: Y. Motoo and P. Zezos

Copyright ( $) 2012$ Sven-Petter Haugvik et al. This is an open access article distributed under the Creative Commons Attribution License, which permits unrestricted use, distribution, and reproduction in any medium, provided the original work is properly cited.

Pancreatic neuroendocrine tumors (PNETs) are rare neoplasms. They are clinically diverse and divided into functioning and nonfunctioning disease, depending on their ability to produce symptoms due to hormone production. Surgical resection is the only curative treatment and remains the cornerstone therapy for this patient group, even in patients with advanced disease. Over the last decade there has been a noticeable trend towards more aggressive surgery as well as more minimally invasive surgery in patients with PNETs. This has resulted in improved long-term survival in patients with locally advanced and metastatic disease treated aggressively, as well as shorter hospital stays and comparable long-term outcomes in patients with limited disease treated minimally invasively. There are still controversies related to issues of surgical treatment of PNETs, such as to what extent enucleation, lymph node sampling, and vascular reconstruction are beneficial for the oncologic outcome. Histopathologic tumor classification is of high clinical importance for treatment planning and prognostic evaluation of patients with PNETs. A constant challenge, which relates to the treatment of PNETs, is the lack of an internationally accepted histopathological classification system. This paper reviews current issues on the surgical treatment of sporadic PNETs with specific focus on surgical approaches and tumor classification.

\section{Epidemiology}

Pancreatic neuroendocrine tumors (PNETs) are rare and account for about $1-2 \%$ of all pancreatic neoplasms $[1,2]$. The incidence has increased during the last decades to 4-5 per 100,000 in the general population [3-5]. Autopsy studies have shown that PNETs can be identified in as many as $10 \%$ of the population, suggesting that many carry asymptomatic disease [6]. Ten to $15 \%$ of all PNETs are part of familial syndromes such as multiple endocrine neoplasia type 1, von Hippel-Lindau, neurofibromatosis and tuberous sclerosis [3], which will not be reviewed further in this paper. The tumorigenesis and molecular pathogenesis of PNETs remain poorly understood.

\section{Clinical Presentation}

PNETs are clinically diverse and divided into functioning and nonfunctioning disease, dependent on their ability to produce symptoms due to hormone production [7]. The distinction between nonfunctioning and functioning PNETs is based on immunohistochemistry of tumor tissue in addition to clinical symptoms. Thirty to $50 \%$ of all PNETs are nonfunctioning $[8,9]$. Since nonfunctioning tumors do not cause hormone-dependent symptoms, they are often detected incidentally or through symptoms related to mass effect resulting from local or distant tumor progression [10]. Common symptoms of nonfunctioning PNETs are abdominal pain, nausea and/or vomiting, fatigue, obstructive 
Table 1: Tumor-node-metastasis definitions in the European Neuroendocrine Tumor Society (ENETS) for staging for pancreatic neuroendocrine tumors $[14,15]$.

\begin{tabular}{|c|c|}
\hline \multicolumn{2}{|c|}{$\mathrm{T}$-primary tumor } \\
\hline $\mathrm{Tx}$ & Primary tumor cannot be assessed \\
\hline T0 & No evidence of primary tumor \\
\hline $\mathrm{T} 1$ & $\begin{array}{l}\text { Tumor limited to the pancreas and size } \\
<2 \mathrm{~cm}\end{array}$ \\
\hline $\mathrm{T} 2$ & $\begin{array}{l}\text { Tumor limited to the pancreas and size } \\
2-4 \mathrm{~cm}\end{array}$ \\
\hline T3 & $\begin{array}{l}\text { Tumor limited to the pancreas and size } \\
>4 \mathrm{~cm} \text { or invading duodenum or bile } \\
\text { duct }\end{array}$ \\
\hline $\mathrm{T} 4$ & $\begin{array}{l}\text { Tumor invading adjacent organs } \\
\text { (stomach, spleen, colon, adrenal } \\
\text { gland) or wall of large vessels (celiac } \\
\text { axis or superior mesenteric artery) }\end{array}$ \\
\hline \multicolumn{2}{|c|}{$\begin{array}{l}\mathrm{N} \text {-regional lymph } \\
\text { nodes }\end{array}$} \\
\hline $\mathrm{Nx}$ & $\begin{array}{l}\text { Regional lymph node cannot be } \\
\text { assessed }\end{array}$ \\
\hline N0 & No regional lymph node metastasis \\
\hline N1 & Regional lymph node metastasis \\
\hline \multicolumn{2}{|c|}{$\mathrm{M}$-distant metastasis } \\
\hline $\mathrm{Mx}$ & Distant metastasis cannot be assessed \\
\hline M0 & No distant metastasis \\
\hline M1 & Distant metastasis \\
\hline
\end{tabular}

jaundice, and abdominal mass [11, 12]. Patients with functioning PNETs, such as insulinoma and gastrinoma, often present with characteristic symptoms dependent on the hormones produced. However, the clinical relevance of the distinction between functioning and nonfunctioning PNETs has recently been questioned as the treatment of these tumors follow the same general principles [13].

\section{Classification}

Classification systems enable patient risk stratifications and directly impact clinical decision making [16]. PNETs are generally classified according to their tumor-node-metastasis (TNM) pattern, defined by TNM staging systems, and grading, defined by the WHO 2010 classification $[4,17]$. The latter is based on the tumor antigen and cell proliferation marker Ki-67. A Ki-67 of below 2\% corresponds to a neuroendocrine tumor (NET) G1, a Ki-67 of 2-20\% corresponds to a NET G2, whereas a Ki-67 above $20 \%$ corresponds to a neuroendocrine carcinoma (NEC) G3 [17]. Beside the generally accepted grading system, there are currently two TNM staging systems that are applied for staging of PNET. One system was proposed by the International Union for Cancer Control, American Joint Cancer Committee and the World Health Organization (UICC/AJCC/WHO), and is widely used in the North American region, while the other system was proposed by the European Neuroendocrine
TABLE 2: Pathology report recommendations for pancreatic neuroendocrine tumors (PNETs) [4].

Macroscopic description

(i) Exact anatomical site

(ii) Margins distance

(iii) Size of the lesion

Microscopic description

(i) Description inclusive of all relevant aspects according to specific anatomical site (structure, necrosis, etc.)

(ii) Supporting immunohistochemistry

(iii) Mitotic count per $10 \mathrm{HPF}\left(2 \mathrm{~mm}^{2}\right)$ and number of mitoses assessed in $50 \mathrm{HPF}$

(iv) Ki-67 index per 400-2,000 cells (hot spots)

(v) Node status

(vi) Margins status

Diagnosis

(i) Definition (NET or NEC)

(ii) Cell component (functioning cases only)

(iii) Grade (1, 2, or 3)

(iv) Tumor-node-metastasis stage

HPF: high-power field; NEC: neuroendocrine carcinoma; NET: neuroendocrine tumor.

Tumor Society (ENETS) and is predominant in the European region $[14,15,18]$. Several studies have demonstrated the usefulness of the ENETS TNM staging system [14, 19-22] and in a recent study, Rindi et al. found that the ENETS TNM staging system is superior to the UICC/AJCC/WHO 2010 TNM staging system in terms of prognostic stratification for patients with PNETs [14]. The ENETS TNM staging system is shown in Table 1. The final classification of PNETs is based on histopathological examination. The histology report should include a minimum set of criteria, including (1) a macroscopic description of the surgical specimen with exact anatomical site, margins distance, and size of the lesion, (2) a microscopic description with supporting immunohistochemistry, mitotic count, Ki-67 index, node-, and margin status, and (3) diagnosis with distinction between NET and NEC, grade, and TNM stage (Table 2).

\section{Surgery}

Surgical resection is the only curative treatment for patients with PNETs and remains the cornerstone therapy [11,23$26]$, even in patients with advanced disease. The goals for surgical resection are cure, relief from functioning tumors [27], or relief from nonfunctioning tumors causing symptoms related to mass effect (biliary obstruction, gastric outlet obstruction, abdominal pain, gastrointestinal hemorrhage). Resectability rates up to $65 \%$ have been reported [28]. However, a substantial portion of patients with PNETs initially present with advanced disease, which cannot be radically resected. 


\subsection{Surgical Approaches}

4.1.1. Functioning Disease. Functioning PNETs primarily include insulinomas and gastrinomas, with an incidence of $70-80 \%$ and $20-25 \%$ of all PNETs, and an incidence of malignancy of $<10 \%$ and $50-60 \%$, respectively [9].

Insulinomas are generally solitary, benign, and curable with surgery $[9,28,29]$. Recurrence after resection occurs in about $3 \%[30,31]$. The procedures of choice are enucleation for small and isolated insulinomas and partial pancreatectomy for large and potentially malignant insulinomas $[32,33]$. Beside enucleation, middle pancreatectomy is an alternative parenchyma-sparing technique for this tumor entity [34]. Also, laparoscopic management of insulinoma in the body and tail of the pancreas, with distal pancreatectomy or enucleation, is feasible and safe [35]. In the case of occult insulinoma, blind distal pancreatectomy should be avoided [36]. However, explorative surgery with intraoperative ultrasound may be indicated in cases where preoperative diagnostics could not reveal any pancreatic lesions, as this is an excellent method for identifying occult insulinoma [37].

Gastrinoma is associated with gastric ulcerations due to overproduction of gastrin [38]. The clinical presentation of gastrinoma is referred to as Zollinger-Ellison syndrome. With the introduction of proton pump inhibitors, which prevent ulcer formation, surgery changed from being symptomatic to curative treatment in patients with ZollingerEllison syndrome [28]. All patients with Zollinger-Ellison syndrome without multiple neuroendocrine neoplasia type 1 or metastatic disease should be offered surgical exploration for possible cure [39]. Routine use of duodenotomy in cases of pancreatic gastrinoma increases short- and long-term cure rates due to a higher detection rate of duodenal gastrinomas, as multiple gastrinomas are relatively common [40].

The incidences of other functioning PNETs, such as vasoactive intestinal peptide-producing tumors (VIPoma), glucagonoma, and somatostatinoma, are very low. These patients should undergo tumor resection to correct the severe hormonally caused metabolic derangements [28].

4.1.2. Nonfunctioning Disease. Nonfunctioning PNETs represent $30-50 \%$ of all PNETs and malignancy occurs in 60 $90 \%[8,9,41]$. Even though curative surgery is rare in patients with nonfunctioning PNETs, long-term survival can be achieved in many patients [12]. There is a strict correlation between tumor size and malignancy in these tumors [42]. Tumors larger than $2 \mathrm{~cm}$ have an increased risk of malignancy [43]. Solitary benign nonfunctioning PNETs can be removed by enucleation or spleen- or duodenumpreserving techniques in most cases [8].

4.1.3. Neuroendocrine Carcinoma. Neuroendocrine carcinomas (NECs) are defined as neuroendocrine tumors with a Ki-67 index above 20\%, according to the WHO 2010 classification [17]. Such tumors are highly malignant and typically invade adjacent structures or metastasize before the diagnosis is made [44]. NECs of the pancreas are very rare and account for only about $2-3 \%$ of all PNETs [45-47].
The outcome is generally poor and most patients die within five years after diagnosis [44, 48]. However, curative resections have been reported in single cases [45]. Therefore, radical surgery should be attempted in localized disease [49, 50], while surgery in metastatic disease is not recommended [48].

4.1.4. Locally Advanced Disease. Locally advanced disease extends beyond the limits of the pancreas directly into surrounding organs or tissue, involves regional lymph nodes, or fulfills both of these criteria [5]. As many PNETs are nonfunctioning and slow-growing, a large proportion of these present with locally advanced disease. Resection for locally advanced PNETs is in general technically feasible and can result in favorable disease-free and overall survival in selected patients [51]. However, most patients will develop recurrence [52]. When not operated, patients with locally advanced PNETs may suffer from complications related to local mass effect and infiltrative growth, including gastrointestinal bleeding, vascular/intestinal/biliary obstruction, and occlusion of the superior mesenteric (SMV) or portal vein (PV) [53]. Hill et al. found that resection of the primary tumor in patients with PNETs is associated with improved survival across all stages of disease [54]. Based on this, surgery of locally advanced PNET without metastasis should be attempted. Interestingly, R1 resections of PNET are not associated with a worse overall survival compared to R0 resections $[21,55]$.

4.1.5. Metastatic Disease. PNETs commonly metastasize to the liver. This is especially true for nonfunctioning tumors as these are generally diagnosed at a late stage. In selected patients, resection of the primary PNET in the setting of unresectable but limited hepatic metastases may be indicated [56-58] as this may prolong survival [59-61]. As mentioned earlier, it has been shown that resection of the primary tumor in patients with PNETs is associated with improved survival across all stages of disease [54]. However, there is currently no clear answer to when and whether resection of the primary tumor should be performed in metastatic disease [62].

Surgical resection with curative intent or palliative debulking of more than $90 \%$ of liver metastases from nonfunctioning PNETs provides favorable oncologic outcomes, despite a high recurrence rate [63-65]. Patients with metastatic disease in the liver may profit from liver resection with long-term palliation and possibly cure in onethird of the patients [66]. Number, size, and localization of tumor sites seem less important than performing a complete resection of metastatic tissue from PNETs [67]. Patients with hormonally active liver metastases without prior extrahepatic or synchronous disease have the greatest survival benefit from surgery [63].

Two-stage procedures for synchronous bilobar liver metastases from NET, including portal vein embolization, enables complete resection and good long-term outcome in selected patients [68]. Debulking extends survival although recurrence is expected [69-71]. Surgical treatment of metastatic PNET should be performed in specialized centers and managed with a multidisciplinary approach $[57,72]$. 


\subsection{Technical Aspects}

4.2.1. Resection versus Enucleation. Standard surgical approaches to PNETs include pancreaticoduodenectomy and distal or subtotal pancreatectomy. Middle segment pancreatectomy is an alternative in the management of PNETs located in the neck or body of the pancreas [73]. A general risk of major pancreatic resections is functional impairment of the organ due to loss of parenchyma, resulting in exocrine and/or endocrine insufficiency. Thus, parenchyma-sparing surgical techniques should be attempted when possible. Enucleation is a feasible procedure for the radical treatment of benign and borderline pancreatic neoplasms [74] and is associated with long-term survival, despite a relatively high risk of pancreatic fistula formation [75, 76]. Before enucleating a PNET, it is important to consider where the tumor is located in relation to the main pancreatic duct, as enucleations of tumors located very close to this may result in damage to the pancreatic duct and subsequent pancreatic leakage. Decisions regarding enucleations are highly individual compared to standard resections, underlining the importance of treatment in experienced high-volume institutions. Tumor enucleation is associated with shorter operative time, less intraoperative blood loss, and shorter hospital stay compared to pancreaticoduodenectomy and distal pancreatectomy [74].

4.2.2. Open versus Laparoscopic Surgery. Over the last decade there has been a trend towards more parenchyma-sparing and minimally invasive techniques in the management of PNETs. This shift has not increased morbidity or compromised survival [77]. Laparoscopic surgery for small and solitary PNETs is feasible and safe [78-81]. Advantages of the minimally invasive approach are less intraoperative bleeding [82], faster postoperative recovery [83], shorter hospital stay $[84,85]$, and improved cosmesis, compared to the open approach.

Laparoscopic distal pancreatectomy (LDP) is today an established procedure at several institutions worldwide [8694]. The procedure provides similar short- and long-term oncologic outcomes as open distal pancreatectomy [85] and a selective use of it also seems to be a cost-efficient alternative to open distal pancreatectomy [82]. LDP with preservation of the spleen is feasible with a moderate risk of postoperative splenic infarction [95]. However, the significance of spleen preservation on oncologic outcome in patients with PNET remains unclear. Beside LDP of PNET in the pancreatic body and tail, laparoscopic enucleation of nonfunctioning PNETs in the pancreatic head [96] and laparoscopic pyloruspreserving pancreatoduodenectomy are feasible procedures that can be considered in selected cases [97]. When performing laparoscopic pancreatic surgery for PNET, intraoperative laparoscopic ultrasound should always be applied, as this allows safe tumor dissection and excision [80]. If the tumor cannot be identified precisely by laparoscopic ultrasound, conversion to open surgery should be considered [98]. Laparoscopic pancreatic surgery demands a high level of surgical skills in minimally invasive surgery and should be performed in specialized centers [99].
4.2.3. Lymph Node Sampling. From studies performed on pancreatic ductal adenocarcinoma, it is known that lymph node status is an important prognostic factor in resectable disease [100-102]. This has also been demonstrated in studies on PNET, where lymph node ratio is a significant predictor of recurrence after curative resection for malignant PNETs [103], and lymph node metastases in PNETs are related to better survival [104]. In many surgical specimens of PNETs, lymph nodes are not evaluated by the pathologist [105]. This may result in understaging of patients with potentially inadequate resection. It is of great importance to know to what extent parenchyma-sparing and minimally invasive pancreatic surgery can provide sufficient lymph node sampling for optimal oncologic outcome. When compared to open surgery, there are studies concluding with a clear limitation of LDP [84] as well as studies concluding with a comparable lymph node sampling after LDP [63]. Enucleations are associated with a low lymph node sampling rate compared with standard resections [105]. Lymph node sampling should be performed routinely when performing parenchyma-preserving or minimally invasive removal for small PNETs, to avoid understaging [34, 43]. Moreover, frozen-section examination should be performed, and when malignancy is confirmed, oncologically appropriate lymph node dissection is recommended [43].

4.2.4. Vascular Reconstruction. Surgery for locally advanced PNETs with vascular involvement is controversial. Vascular reconstruction has already been established in the treatment of locally advanced pancreatic adenocarcinoma [106]. Several case reports [107-109] suggest that a similar approach is feasible and beneficial in selected patients with PNETs. Norton et al. have recently examined this issue systematically [110]. In their study, only 9 of 42 patients with major vascular abutment undergoing resections of PNETs required vascular reconstruction. This shows that in most cases, even if the radiological evaluation suggests vascular involvement and at surgery the PNET is found to partially encase or involve the vessel, the tumor can be removed with careful dissection without requiring vascular reconstruction. Conventional contraindications to surgical resection of pancreatic malignancy, such as superior mesenteric vein invasion, should be reconsidered in patients with locally advanced PNETs $[52,110]$.

\section{Prognosis and Follow-up}

The five- and 10-year survival rates for all PNETs are about $65 \%$ and $45 \%$, respectively, $[19,111]$. The five-year survival rate for functioning PNETs is about $80 \%$ [111], while the five- and 10-year survival rates for nonfunctioning PNETs are about 55\% and 30\%, respectively, [11, 111]. Definitive surgical resection of the primary tumor, absence of liver metastases, metachronous liver metastases, and aggressive treatment of the liver metastases are predictive factors of long-term survival in patients with PNETs [112].

Long-term follow-up of patients having undergone surgical treatment for nonfunctioning PNETs is essential as there is a risk of late recurrence [34]. There have recently 
TABLE 3: Key points.

Key points

(i) Surgical resection is the only curative treatment for patients with PNETs.

(ii) The incidence of PNETs has increased during the last decades.

(iii) PNETs are clinically diverse and divided in functioning and nonfunctioning disease.

(iv) The ENETS TNM staging system is superior to the UICC/AJCC/WHO 2010 TNM staging system in terms of prognostic stratification for patients with PNETs.

(v) There has been a trend towards more aggressive surgery as well as more minimally invasive surgery in patients with PNETs over the last decade.

(vi) Lymph node sampling should be performed routinely after curative resection of PNETs, as lymph node ratio is a significant predictor of recurrence.

(vii) The five- and 10-year survival rates for all PNETs are about $65 \%$ and $45 \%$.

(viii) Long-term followup of patients having undergone surgical treatment for nonfunctioning PNETs is essential due to the risk of late recurrence.

been published several international consensus guidelines on the management of patients with PNETs [113-116], which also include guidelines on follow-up of patients with functioning PNETs [113], nonfunctioning PNETs [114] and NECs [48]. The follow-up of patients with PNETs should be managed by specialized centers with a multidisciplinary approach $[16,57,72,117,118]$.

\section{Conclusions}

In conclusion, this paper shows how sporadic PNETs represent a rare and clinically diverse group of pancreatic neoplasms, which requires special attention from hepatopancreatobiliary surgeons. Even though sporadic PNETs are associated with a high malignant potential, they are generally slow-growing. This explains why conventional contraindications to surgical resection of pancreatic malignancy should be reconsidered in patients with locally advanced or even metastatic disease. There is still a need for an internationally accepted histopathological classification system for PNETs. Recent studies suggest that the ENETS TNM staging system is a reliable system in terms of prognostic stratification. Other key points related to surgical treatment of sporadic PNETs with specific focus on surgical approaches and tumor classification are shown in Table 3.

\section{Conflict of Interests}

There is no conflict of interests.

\section{References}

[1] T. R. Halfdanarson, K. G. Rabe, J. Rubin, and G. M. Petersen, "Pancreatic neuroendocrine tumors (PNETs): incidence, prognosis and recent trend toward improved survival," Annals of Oncology, vol. 19, no. 10, pp. 1727-1733, 2008.

[2] S. A. Milan and C. J. Yeo, "Neuroendocrine tumors of the pancreas," Current Opinion in Oncology, vol. 24, no. 1, pp. 46-55, 2012.

[3] K. Öberg, "Pancreatic endocrine tumors," Seminars in Oncology, vol. 37, no. 6, pp. 594-618, 2010.

[4] G. Rindi and B. Wiedenmann, "Neuroendocrine neoplasms of the gut and pancreas: new insights," Nature Reviews Endocrinology, vol. 8, pp. 54-64, 2012.

[5] J. C. Yao, M. Hassan, A. Phan et al., "One hundred years after "carcinoid": epidemiology of and prognostic factors for neuroendocrine tumors in 35,825 cases in the United States," Journal of Clinical Oncology, vol. 26, no. 18, pp. 3063-3072, 2008.

[6] W. Kimura, A. Kuroda, and Y. Morioka, "Clinical pathology of endocrine tumors of the pancreas. Analysis of autopsy cases," Digestive Diseases and Sciences, vol. 36, no. 7, pp. 933942, 1991.

[7] M. H. Kulke, J. Bendell, L. Kvols, J. Picus, R. Pommier, and J. Yao, "Evolving diagnostic and treatment strategies for pancreatic neuroendocrine tumors," Journal of Hematology and Oncology, vol. 4, article no. 29, 2011.

[8] H. Dralle, S. L. Krohn, W. Karges, B. O. Boehm, M. Brauckhoff, and O. Gimm, "Surgery of resectable nonfunctioning neuroendocrine pancreatic tumors," World Journal of Surgery, vol. 28, no. 12, pp. 1248-1260, 2004.

[9] V. Fendrich, J. Waldmann, D. K. Bartsch, and P. Langer, "Surgical management of pancreatic endocrine tumors," Nature Reviews Clinical Oncology, vol. 6, no. 7, pp. 419-428, 2009.

[10] D. B. Evans, J. M. Skibber, J. E. Lee et al., "Nonfunctioning islet cell carcinoma of the pancreas," Surgery, vol. 114, no. 6, pp. 1175-1182, 1993.

[11] H. Liang, P. Wang, X. N. Wang, J. C. Wang, and X. S. Hao, "Management of nonfunctioning islet cell tumors," World Journal of Gastroenterology, vol. 10, no. 12, pp. 1806-1809, 2004.

[12] D. K. Bartsch, T. Schilling, A. Ramaswamy et al., "Management of nonfunctioning islet cell carcinomas," World Journal of Surgery, vol. 24, no. 11, pp. 1418-1424, 2000.

[13] I. M. Modlin, S. F. Moss, B. I. Gustafsson, B. Lawrence, S. Schimmack, and M. Kidd, "The archaic distinction between functioning and nonfunctioning neuroendocrine neoplasms is no longer clinically relevant," Langenbeck's Archives of Surgery, vol. 396, pp. 1145-1156, 2011.

[14] G. Rindi, M. Falconi, C. Klersy et al., "TNM staging of neoplasms of the endocrine pancreas: results from a large international cohort study," Journal of the National Cancer Institute, vol. 104, no. 10, pp. 764-777, 2012.

[15] G. Rindi, G. Klöppel, and H. Alhman, "TNM staging of foregut (neuro)endocrine tumors: a consensus proposal including a grading system," Virchows Archiv, vol. 449, no. 4, pp. 395-401, 2006.

[16] F. Ehehalt, H. D. Saeger, C. M. Schmidt, and R. Grützmann, "Neuroendocrine tumors of the pancreas," Oncologist, vol. 14, no. 5, pp. 456-467, 2009.

[17] F. T. Bosman, F. Carneiro, and R. H. Hruban, WHO Classification of Tumours of the Digestive System, International Agency for Research on Cancer (IARC), Lyon, France, 2010. 
[18] G. Rindi, "The ENETS guidelines: the new TNM classification system," Tumori, vol. 96, no. 5, pp. 806-809, 2010.

[19] S. Ekeblad, B. Skogseid, K. Dunder, K. Oberg, and B. Eriksson, "Prognostic factors and survival in 324 patients with pancreatic endocrine tumor treated at a single institution," Clinical Cancer Research, vol. 14, no. 23, pp. 7798-7803, 2008.

[20] H. Ito, M. Abramson, K. Ito et al., "Surgery and staging of pancreatic neuroendocrine tumors: a 14-year experience," Journal of Gastrointestinal Surgery, vol. 14, no. 5, pp. 891-898, 2010.

[21] E. Pomianowska, I. P. Gladhaug, K. Grzyb et al., "Survival following resection of pancreatic endocrine tumors: importance of R-status and the WHO and TNM classification systems," Scandinavian Journal of Gastroenterology, vol. 45, no. 7-8, pp. 971-979, 2010.

[22] A. Scarpa, W. Mantovani, P. Capelli et al., "Pancreatic endocrine tumors: improved TNM staging and histopathological grading permit a clinically efficient prognostic stratification of patients," Modern Pathology, vol. 23, no. 6, pp. 824-833, 2010.

[23] F. Gomez-Rivera, A. E. Stewart, J. P. Arnoletti, S. Vickers, K. I. Bland, and M. J. Heslin, "Surgical treatment of pancreatic endocrine neoplasms," American Journal of Surgery, vol. 193, no. 4, pp. 460-465, 2007.

[24] A. Legaspi, M. F. Brennan, R. A. Prinz et al., "Management of islet cell carcinoma," Surgery, vol. 104, no. 6, pp. 1018-1023, 1988.

[25] K. K. Kazanjian, H. A. Reber, and O. J. Hines, "Resection of pancreatic neuroendocrine tumors: results of 70 cases," Archives of Surgery, vol. 141, no. 8, pp. 765-769, 2006.

[26] A. Zerbi, V. Capitanio, L. Boninsegna et al., "Surgical treatment of pancreatic endocrine tumours in Italy: results of a prospective multicentre study of 262 cases," Langenbeck's Archives of Surgery, vol. 396, no. 3, pp. 313-321, 2011.

[27] B. D. Matthews, T. I. Smith, K. W. Kercher, W. D. Holder, and B. T. Heniford, "Surgical experience with functioning pancreatic neuroendocrine tumors," American Surgeon, vol. 68, no. 8, pp. 660-665, 2002.

[28] C. S. Grant, "Surgical management of malignant islet cell tumors," World Journal of Surgery, vol. 17, no. 4, pp. 498-503, 1993.

[29] D. Grama, B. Eriksson, H. Martensson et al., "Clinical characteristics, treatment and survival in patients with pancreatic tumors causing hormonal syndromes," World Journal of Surgery, vol. 16, no. 4, pp. 632-639, 1992.

[30] S. Crippa, A. Zerbi, L. Boninsegna et al., "Surgical management of insulinomas: short- and long-term outcomes after enucleations and pancreatic resections," Archives of Surgery, vol. 147, no. 3, pp. 261-266, 2012.

[31] M. Rothmund, L. Angelini, L. M. Brunt et al., "Surgery for benign insulinoma: an international review," World Journal of Surgery, vol. 14, no. 3, pp. 393-399, 1990.

[32] D. Vaidakis, J. Karoubalis, T. Pappa, G. Piaditis, and G. N. Zografos, "Pancreatic insulinoma: current issues and trends," Hepatobiliary and Pancreatic Diseases International, vol. 9, no. 3, pp. 234-241, 2010.

[33] A. Sa Cunha, A. Rault, C. Beau, D. Collet, and B. Masson, "Laparoscopic central pancreatectomy: single institution experience of 6 patients," Surgery, vol. 142, no. 3, pp. 405409, 2007.

[34] M. Falconi, A. Zerbi, S. Crippa et al., "ParenchymaPreserving resections for small nonfunctioning pancreatic endocrine tumors," Annals of Surgical Oncology, vol. 17, no. 6, pp. 1621-1627, 2010.
[35] Y. P. Zhao, H. X. Zhan, T. P. Zhang et al., "Surgical management of patients with insulinomas: result of 292 cases in a single institution," Journal of Surgical Oncology, vol. 103, no. 2, pp. 169-174, 2011.

[36] B. Hirshberg, S. K. Libutti, H. R. Alexander et al., "Blind distal pancreatectomy for occult insulinoma, an inadvisable procedure," Journal of the American College of Surgeons, vol. 194, no. 6, pp. 761-764, 2002.

[37] J. A. Norton, T. H. Shawker, J. L. Doppman et al., "Localization and surgical treatment of occult insulinomas," Annals of Surgery, vol. 212, no. 5, pp. 615-620, 1990.

[38] E. C. Ellison, J. Sparks, J. S. Verducci et al., "50-year appraisal of gastrinoma: recommendations for staging and treatment," Journal of the American College of Surgeons, vol. 202, no. 6, pp. 897-905, 2006.

[39] J. A. Norton, D. L. Fraker, H. R. Alexander et al., "Surgery to cure the Zollinger-Ellison syndrome," The New England Journal of Medicine, vol. 341, no. 9, pp. 635-644, 1999.

[40] J. A. Norton, H. R. Alexander, D. L. Fraker et al., "Does the use of routine duodenotomy (DUODX) affect rate of cure, development of liver metastases, or survival in patients with Zollinger-Ellison syndrome?" Annals of Surgery, vol. 239, no. 5, pp. 617-626, 2004.

[41] F. E. Eckhauser, P. S. Cheung, and A. I. Vinik, "Nonfunctioning malignant neuroendocrine tumors of the pancreas," Surgery, vol. 100, no. 6, pp. 978-988, 1986.

[42] R. Bettini, S. Partelli, L. Boninsegna et al., "Tumor size correlates with malignancy in nonfunctioning pancreatic endocrine tumor," Surgery, vol. 150, no. 1, pp. 75-82, 2011.

[43] L. Fernández-Cruz, V. Molina, R. Vallejos, E. Jiménez Chavarria, M.-A. Lõpez-Boado, and J. Ferrer, "Outcome after laparoscopic enucleation for non-functional neuroendocrine pancreatic tumours," $H P B$, vol. 14, no. 3, pp. 171-176, 2012.

[44] F. Panzuto, L. Boninsegna, N. Fazio et al., "Metastatic and locally advanced pancreatic endocrine carcinomas: analysis of factors associated with disease progression," Journal of Clinical Oncology, vol. 29, no. 17, pp. 2372-2377, 2011.

[45] K. Kinoshita, T. Minami, Y. Ohmori, S. Kanayama, K. Yoshikawa, and T. Tsujimura, "Curative resection of a small cell carcinoma of the pancreas: report of a case of long survival without chemotherapy," Journal of Gastroenterology and Hepatology, vol. 19, no. 9, pp. 1087-1091, 2004.

[46] T. P. O'Connor, T. P. Wade, Y. C. Sunwoo et al., "Small cell undifferentiated carcinoma of the pancreas: report of a patient with tumor marker studies," Cancer, vol. 70, no. 6, pp. 1514-1519, 1992.

[47] C. V. Reyes and T. Wang, "Undifferentiated small cell carcinoma of the pancreas: a report of five cases," Cancer, vol. 47, no. 10, pp. 2500-2502, 1981.

[48] O. Nilsson, E. Van Cutsem, G. Delle Fave et al., "Poorly differentiated carcinomas of the foregut (gastric, duodenal and pancreatic)," Neuroendocrinology, vol. 84, no. 3, pp. 212215, 2007.

[49] L. Kölby, O. Nilsson, and H. Ahlman, "Gastroduodenal endocrine tumours," Scandinavian Journal of Surgery, vol. 93, no. 4, pp. 317-323, 2004.

[50] G. Åkerström, "Management of carcinoid tumors of the stomach, duodenum, and pancreas," World Journal of Surgery, vol. 20, no. 2, pp. 173-182, 1996.

[51] M. Abu Hilal, M. J. W. McPhail, B. A. Zeidan, C. E. Jones, C. D. Johnson, and N. W. Pearce, "Aggressive multi-visceral pancreatic resections for locally advanced neuroendocrine tumours. Is it worth it?" Journal of the Pancreas, vol. 10, no. 3, pp. 276-279, 2009. 
[52] J. A. Norton, M. Kivlen, M. Li et al., "Morbidity and mortality of aggressive resection in patients with advanced neuroendocrine tumors," Archives of Surgery, vol. 138, no. 8, pp. 859-866, 2003.

[53] P. Hellman, M. Andersson, J. Rastad et al., "Surgical strategy for large or malignant endocrine pancreatic tumors," World Journal of Surgery, vol. 24, no. 11, pp. 1353-1360, 2000.

[54] J. S. Hill, J. T. McPhee, T. P. McDade et al., "Pancreatic neuroendocrine tumors," Cancer, vol. 115, no. 4, pp. 741751, 2009.

[55] E. S. Glazer, J. F. Tseng, W. Al-Refaie et al., "Long-term survival after surgical management of neuroendocrine hepatic metastases," HPB, vol. 12, no. 6, pp. 427-433, 2010.

[56] M. Bruzoni, P. Parikh, R. Celis et al., "Management of the primary tumor in patients with metastatic pancreatic neuroendocrine tumor: a contemporary single-institution review," American Journal of Surgery, vol. 197, no. 3, pp. 376381, 2009.

[57] R. S. Chamberlain, D. Canes, K. T. Brown et al., "Hepatic neuroendocrine metastases: does intervention alter outcomes?" Journal of the American College of Surgeons, vol. 190, no. 4, pp. 432-445, 2000.

[58] C. S. Cho, D. M. Labow, L. Tang et al., "Histologic grade is correlated with outcome after resection of hepatic neuroendocrine neoplasms," Cancer, vol. 113, no. 1, pp. 126134, 2008.

[59] H. Chen, J. M. Hardacre, A. Uzar, J. L. Cameron, and M. A. Choti, "Isolated liver metastases from neuroendocrine tumors: does resection prolong survival?" Journal of the American College of Surgeons, vol. 187, no. 1, pp. 88-92, 1998.

[60] S. Musunuru, H. Chen, S. Rajpal et al., "Metastatic neuroendocrine hepatic tumors: resection improves survival," Archives of Surgery, vol. 141, no. 10, pp. 1000-1004, 2006.

[61] F. G. Que, D. M. Nagorney, K. P. Batts, L. J. Linz, and L. K. Kvols, "Hepatic resection for metastatic neuroendocrine carcinomas," American Journal of Surgery, vol. 169, no. 1, pp. 36-43, 1995.

[62] G. Capurso, R. Bettini, M. Rinzivillo, L. Boninsegna, G. D. Fave, and M. Falconi, "Role of resection of the primary pancreatic neuroendocrine tumour only in patients with unresectable metastatic liver disease: a systematic review," Neuroendocrinology, vol. 93, no. 4, pp. 223-229, 2011.

[63] S. C. Mayo, M. C. De Jong, C. Pulitano et al., "Surgical management of hepatic neuroendocrine tumor metastasis: results from an international multi-institutional analysis," Annals of Surgical Oncology, vol. 17, no. 12, pp. 3129-3136, 2010.

[64] S. Scigliano, R. Lebtahi, F. Maire et al., "Clinical and imaging follow-up after exhaustive liver resection of endocrine metastases: a 15-year monocentric experience," Endocrine-Related Cancer, vol. 16, no. 3, pp. 977-990, 2009.

[65] D. Cusati, L. Zhang, W. S. Harmsen et al., "Metastatic nonfunctioning pancreatic neuroendocrine carcinoma to liver: surgical treatment and outcomes," Journal of the American College of Surgeons, vol. 215, no. 1, pp. 117-124, 2012.

[66] B. Dousset, O. Saint-Marc, J. Pitre, O. Soubrane, D. Houssin, and Y. Chapuis, "Metastatic endocrine tumors: medical treatment, surgical resection, or liver transplantation," World Journal of Surgery, vol. 20, no. 7, pp. 908-915, 1996.

[67] D. Elias, P. Lasser, M. Ducreux et al., "Liver resection (and associated extrahepatic resections) for metastatic welldifferentiated endocrine tumors: a 15-year single center prospective study," Surgery, vol. 133, no. 4, pp. 375-382, 2003.
[68] R. Kianmanesh, A. Sauvanet, O. Hentic et al., "Two-step surgery for synchronous bilobar liver metastases from digestive endocrine tumors: a safe approach for radical resection," Annals of Surgery, vol. 247, no. 4, pp. 659-665, 2008.

[69] J. M. Sarmiento, G. Heywood, J. Rubin, D. M. Ilstrup, D. M. Nagorney, and F. G. Que, "Surgical treatment of neuroendocrine metastases to the liver: a plea for resection to increase survival," Journal of the American College of Surgeons, vol. 197, no. 1, pp. 29-37, 2003.

[70] J. M. Sarmiento and F. G. Que, "Hepatic surgery for metastases from neuroendocrine tumors," Surgical Oncology Clinics of North America, vol. 12, no. 1, pp. 231-242, 2003.

[71] G. B. Thompson, J. A. Van Heerden, C. S. Grant, J. A. Carney, and D. M. Ilstrup, "Islet cell carcinomas of the pancreas: a twenty-year experience," Surgery, vol. 104, no. 6, pp. 10111017, 1988.

[72] G. L. Grazi, M. Cescon, F. Pierangeli et al., "Highly aggressive policy of hepatic resections for neuroendocrine liver metastases," Hepato-Gastroenterology, vol. 47, no. 32, pp. 481-486, 2000.

[73] C. Bassi, "Middle segment pancreatectomy: a useful tool in the management of pancreatic neoplasms," Journal of Gastrointestinal Surgery, vol. 11, no. 4, pp. 421-424, 2007.

[74] T. Hackert, U. Hinz, S. Fritz et al., "Enucleation in pancreatic surgery: indications, technique, and outcome compared to standard pancreatic resections," Langenbeck's Archives of Surgery, vol. 396, pp. 1197-1203, 2011.

[75] S. Crippa, C. Bassi, R. Salvia, M. Falconi, G. Butturini, and P. Pederzoli, "Enucleation of pancreatic neoplasms," British Journal of Surgery, vol. 94, no. 10, pp. 1254-1259, 2007.

[76] A. Dedieu, A. Rault, D. Collet, B. Masson, and A. Sa Cunha, "Laparoscopic enucleation of pancreatic neoplasm," Surgical Endoscopy and Other Interventional Techniques, vol. 25, no. 2, pp. 575-576, 2011.

[77] J. DiNorcia, M. K. Lee, P. L. Reavey et al., "One hundred thirty resections for pancreatic neuroendocrine tumor: evaluating the impact of minimally invasive and parenchyma-sparing techniques," Journal of Gastrointestinal Surgery, vol. 14, no. 10, pp. 1536-1546, 2010.

[78] A. Assalia and M. Gagner, "Laparoscopic pancreatic surgery for islet cell tumors of the pancreas," World Journal of Surgery, vol. 28, no. 12, pp. 1239-1247, 2004.

[79] B. Edwin, T. Mala, O. Mathisen et al., "Laparoscopic resection of the pancreas: a feasibility study of the shortterm outcome," Surgical Endoscopy and Other Interventional Techniques, vol. 18, no. 3, pp. 407-411, 2004.

[80] L. Fernández-Cruz, M. Herrera, A. Sáenz, J. P. Pantoja, E. Astudillo, and M. Sierra, "Laparoscopic pancreatic surgery in patients with neuroendocrine tumours: indications and limits," Best Practice and Research, vol. 15, no. 2, pp. 161-175, 2001.

[81] M. Gagner, A. Pomp, M. F. Herrera et al., "Early experience with laparoscopic resections of islet cell tumors," Surgery, vol. 120, no. 6, pp. 1051-1054, 1996.

[82] P. Limongelli, A. Belli, G. Russo et al., "Laparoscopic and open surgical treatment of left-sided pancreatic lesions: clinical outcomes and cost-effectiveness analysis," Surgical Endoscopy and Other Interventional Techniques, vol. 26, no. 7, pp. 1830-1836, 2012.

[83] S. C. Kim, K. T. Park, J. W. Hwang et al., "Comparative analysis of clinical outcomes for laparoscopic distal pancreatic resection and open distal pancreatic resection at a single institution," Surgical Endoscopy and Other Interventional Techniques, vol. 22, no. 10, pp. 2261-2268, 2008. 
[84] M. S. Baker, D. J. Bentrem, M. B. Ujiki, S. Stocker, and M. S. Talamonti, "A prospective single institution comparison of peri-operative outcomes for laparoscopic and open distal pancreatectomy," Surgery, vol. 146, no. 4, pp. 635-645, 2009.

[85] D. A. Kooby, W. G. Hawkins, C. M. Schmidt et al., "Curative laparoscopic resection for pancreatic neoplasms: a critical analysis from a single institution," Journal of the American College of Surgeons, vol. 210, no. 5, pp. 779-785, 2010.

[86] L. Fernández-Cruz, R. Cosa, L. Blanco, S. Levi, M. A. LópezBoado, and S. Navarro, "Curative laparoscopic resection for pancreatic neoplasms: a critical analysis from a single institution," Journal of Gastrointestinal Surgery, vol. 11, no. 12, pp. 1607-1622, 2007.

[87] J. Y. Mabrut, L. Fernandez-Cruz, J. S. Azagra et al., "Laparoscopic pancreatic resection: results of a multicenter European study of 127 patients," Surgery, vol. 137, no. 6, pp. 597-605, 2005.

[88] B. W. Eom, J. Y. Jang, S. E. Lee, H. S. Han, Y. S. Yoon, and S. W. Kim, "Clinical outcomes compared between laparoscopic and open distal pancreatectomy," Surgical Endoscopy and Other Interventional Techniques, vol. 22, no. 5, pp. 13341338, 2008.

[89] M. A. Hilal, M. Hamdan, F. Di Fabio, N. W. Pearce, and C. D. Johnson, "Laparoscopic versus open distal pancreatectomy: a clinical and cost-effectiveness study," Surgical Endoscopy and Other Interventional Techniques, vol. 26, no. 6, pp. 16701674, 2012.

[90] D. A. Kooby, T. Gillespie, D. Bentrem et al., "Left-sided pancreatectomy: a multicenter comparison of laparoscopic and open approaches," Annals of Surgery, vol. 248, no. 3, pp. 438-443, 2008.

[91] B. I. Røsok, I. P. Marangos, A. M. Kazaiyan et al., "Singlecentre experience of laparoscopic pancreatic surgery," British Journal of Surgery, vol. 97, no. 6, pp. 902-909, 2010.

[92] P. J. Kneuertz, S. H. Patel, C. K. Chu et al., "Laparoscopic distal pancreatectomy: trends and lessons learned through an 11-year experience," Journal of the American College of Surgeons, vol. 215, no. 2, pp. 167-176, 2012.

[93] A. M. Fox, K. Pitzul, F. Bhojani et al., "Comparison of outcomes and costs between laparoscopic distal pancreatectomy and open resection at a single center," Surgical Endoscopy and Other Interventional Techniques, vol. 26, no. 5, pp. 12201230, 2012.

[94] G. Butturini, S. Partelli, S. Crippa et al., "Perioperative and long-term results after left pancreatectomy: a singleinstitution, non-randomized, comparative study between open and laparoscopic approach," Surgical Endoscopy, vol. 25, pp. 2871-2878, 2011.

[95] G. Butturini, M. Inama, G. Malleo et al., "Perioperative and long-term results of laparoscopic spleen-preserving distal pancreatectomy with or without splenic vessels conservation: a retrospective analysis," Journal of Surgical Oncology, vol. 105, no. 4, pp. 387-392, 2012.

[96] N. Singh, C. Y. Lo, and W. F. Chan, "Laparoscopic enucleation of a nonfunctioning neuroendocrine tumor at the head of the pancreas," JSLS, vol. 10, no. 2, pp. 259-262, 2006.

[97] S. C. Kim, K. B. Song, Y. S. Jung et al., "Short-term clinical outcomes for 100 consecutive cases of laparoscopic pylorus-preserving pancreatoduodenectomy: improvement with surgical experience," Surgical Endoscopy. In press.

[98] L. Fernández-Cruz and G. Cesar-Borges, "Laparoscopic strategies for resection of insulinomas," Journal of Gastrointestinal Surgery, vol. 10, no. 5, pp. 752-760, 2006.
[99] A. Toniato, F. Meduri, M. Foletto, A. Avogaro, and M. Pelizzo, "Laparoscopic treatment of benign insulinomas localized in the body and tail of the pancreas: a single-center experience," World Journal of Surgery, vol. 30, no. 10, pp. 1916-1919, 2006.

[100] Y. Murakami, K. Uemura, T. Sudo et al., "Number of metastatic lymph nodes, but not lymph node ratio, is an independent prognostic factor after resection of pancreatic carcinoma," Journal of the American College of Surgeons, vol. 211, no. 2, pp. 196-204, 2010.

[101] T. T. Sahin, T. Fujii, M. Kanda et al., "Prognostic implications of lymph node metastases in carcinoma of the body and tail of the pancreas," Pancreas, vol. 40, pp. 1029-1033, 2011.

[102] E. Pomianowska, A. Westgaard, O. Mathisen et al., "Prognostic relevance of number and ratio of metastatic lymph nodes in resected pancreatic, ampullary, and distal bile duct carcinomas," Annals of Surgical Oncology. In press.

[103] L. Boninsegna, F. Panzuto, S. Partelli et al., "Malignant pancreatic neuroendocrine tumour: lymph node ratio and Ki67 are predictors of recurrence after curative resections," European Journal of Cancer, vol. 48, no. 11, pp. 1608-1615, 2012.

[104] P. Tomassetti, D. Campana, L. Piscitelli et al., "Endocrine pancreatic tumors: factors correlated with survival," Annals of Oncology, vol. 16, no. 11, pp. 1806-1810, 2005.

[105] J. R. Parekh, S. C. Wang, E. K. Bergsland et al., "Lymph node sampling rates and predictors of nodal metastasis in pancreatic neuroendocrine tumor resections: the ucsf experience with 149 patients," Pancreas, vol. 41, no. 6, pp. 840-844, 2012.

[106] M. Ouaissi, C. Hubert, R. Verhelst et al., "Vascular reconstruction during pancreatoduodenectomy for ductal adenocarcinoma of the pancreas improves resectability but does not achieve cure," World Journal of Surgery, vol. 34, no. 11, pp. 2648-2661, 2010.

[107] T. Akatsu, K. Aiura, M. Shimazu et al., "Successful pancreatectomy with En-bloc resection of the celiac artery and portal vein for pancreatic endocrine carcinoma," HepatoGastroenterology, vol. 54, no. 76, pp. 1269-1271, 2007.

[108] A. Bedirli, T. E. Patiroglu, O. Sakrak, and Y. Aritas, "Portal vein resection for a portal vein thrombus caused by nonfunctioning islet cell carcinoma: report of a case," Surgery Today, vol. 34, no. 9, pp. 802-804, 2004.

[109] E. Sakamoto, H. Hasegawa, S. Ogiso et al., "Curative resection for a pancreatic endocrine carcinoma involving the portal vein," Hepato-Gastroenterology, vol. 51, no. 60, pp. 1849-1851, 2004.

[110] J. A. Norton, E. J. Harris, Y. Chen et al., "Pancreatic endocrine tumors with major vascular abutment, involvement, or encasement and indication for resection," Archives of Surgery, vol. 146, no. 6, pp. 724-732, 2011.

[111] G. Q. Phan, C. J. Yeo, R. H. Hruban, K. D. Lillemoe, H. A. Pitt, and J. L. Cameron, "Surgical experience with pancreatic and peripancreatic neuroendocrine tumors: review of 125 patients," Journal of Gastrointestinal Surgery, vol. 2, no. 5, pp. 473-482, 1998.

[112] Q. D. Chu, H. C. Hill, H. O. Douglass et al., "Predictive factors associated with long-term survival in patients with neuroendocrine tumors of the pancreas," Annals of Surgical Oncology, vol. 9, no. 9, pp. 855-862, 2002.

[113] R. T. Jensen, G. Cadiot, M. L. Brandi et al., "ENETS consensus guidelines for the management of patients with digestive neuroendocrine neoplasms: functional pancreatic 
endocrine tumor syndromes," Neuroendocrinology, vol. 95, no. 2, pp. 98-119, 2012.

[114] M. Falconi, D. K. Bartsch, B. Eriksson et al., "ENETS consensus guidelines for the management of patients with digestive neuroendocrine neoplasms of the digestive system: well-differentiated pancreatic non-functioning tumors," Neuroendocrinology, vol. 95, no. 2, pp. 120-134, 2012.

[115] E. T. Janson, H. Sørbye, S. Welin et al., "Nordic Guidelines 2010 for diagnosis and treatment of gastroenteropancreatic neuroendocrine tumours," Acta Oncologica, vol. 49, no. 6, pp. 740-756, 2010.

[116] M. H. Kulke, L. B. Anthony, D. L. Bushnell et al., "NANETS treatment guidelines: well-differentiated neuroendocrine tumors of the stomach and pancreas," Pancreas, vol. 39, no. 6, pp. 735-752, 2010.

[117] M. A. Kouvaraki, C. C. Solorzano, S. E. Shapiro et al., "Surgical treatment of non-functioning pancreatic islet cell tumors," Journal of Surgical Oncology, vol. 89, no. 3, pp. 170185, 2005.

[118] S. L. Ong, G. Garcea, C. A. Pollard et al., "A fuller understanding of pancreatic neuroendocrine tumours combined with aggressive management improves outcome," Pancreatology, vol. 9, no. 5, pp. 583-600, 2009. 


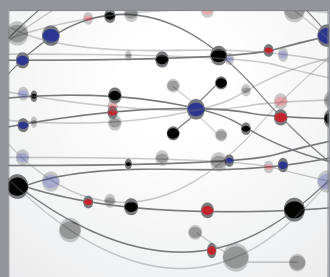

The Scientific World Journal
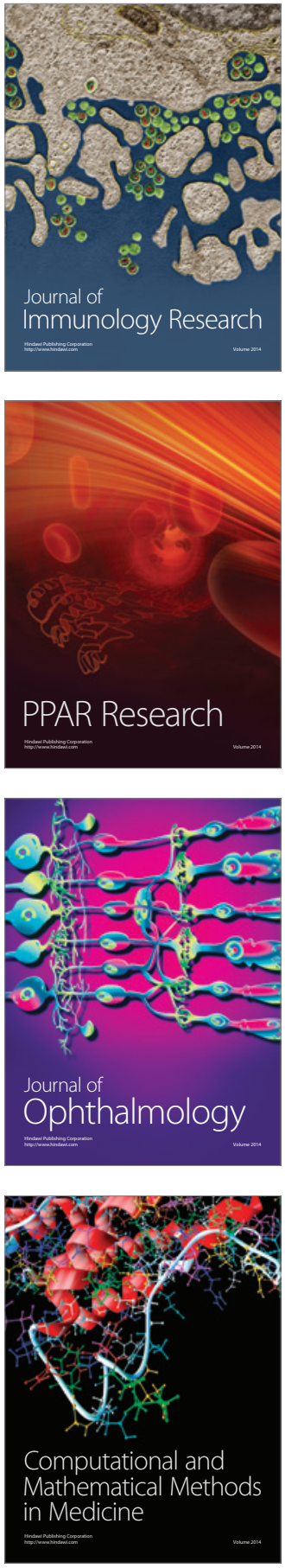

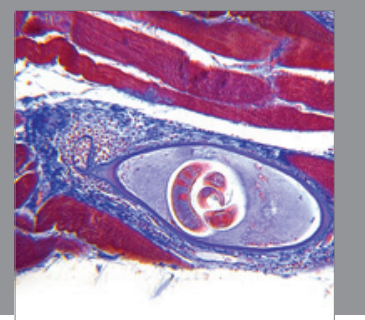

Gastroenterology

Research and Practice
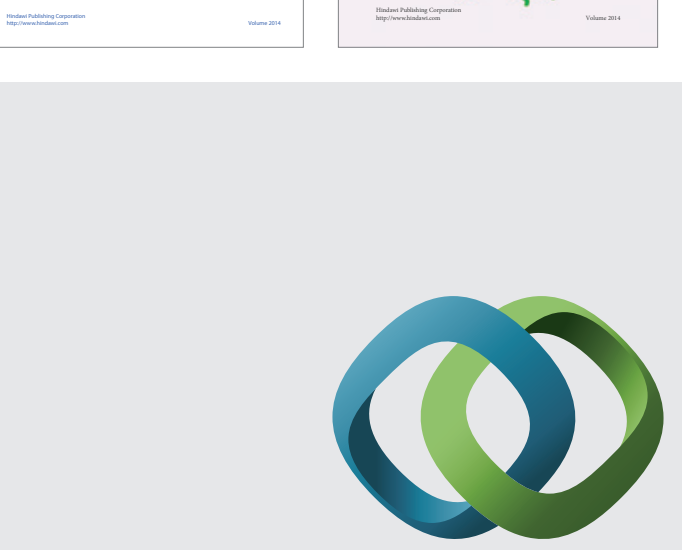

\section{Hindawi}

Submit your manuscripts at

http://www.hindawi.com
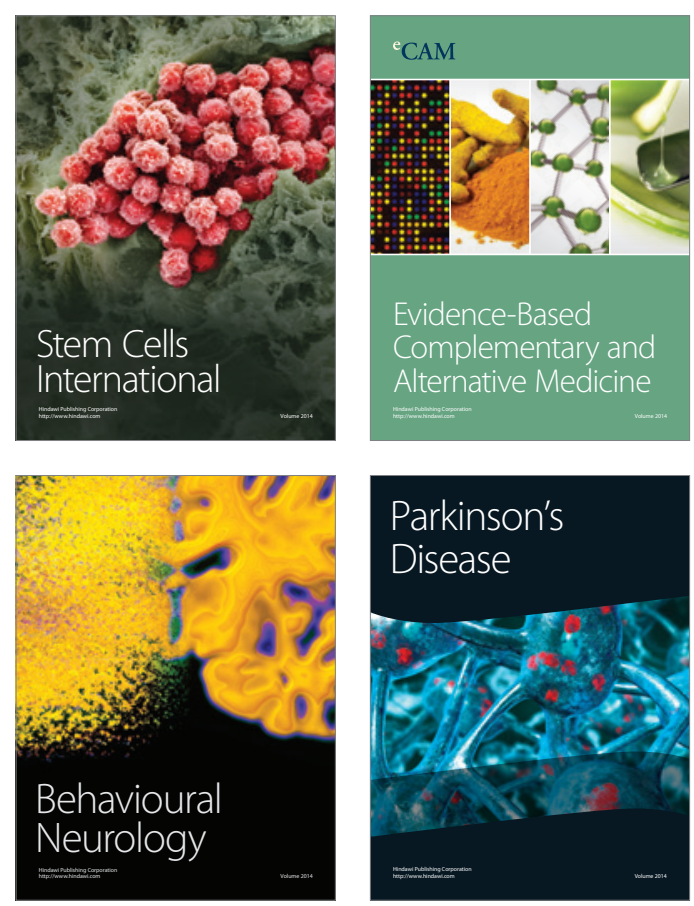

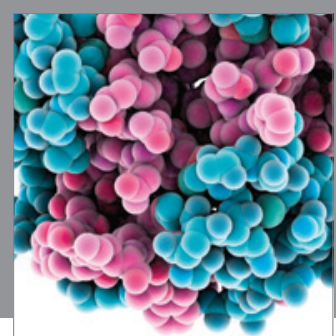

Journal of
Diabetes Research

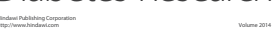

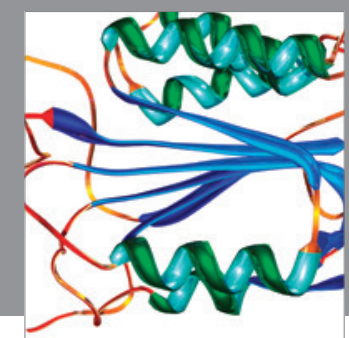

Disease Markers
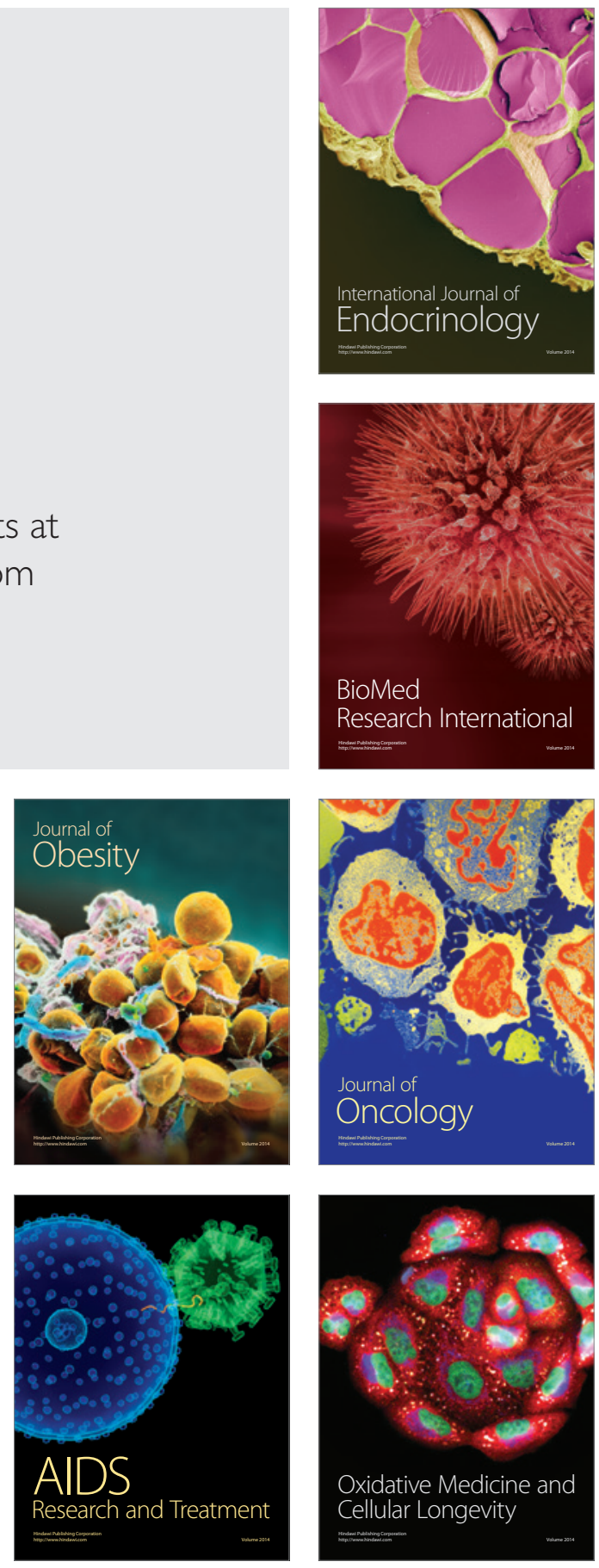